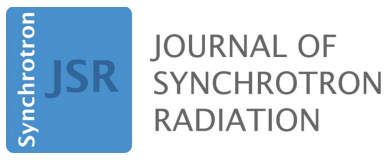

ISSN 1600-5775

Received 27 April 2019

Accepted 25 November 2019

Edited by A. F. Craievich, University of São Paulo, Brazil

Keywords: molecular ice; nitriles; planetary atmospheres; Titan.

Supporting information: this article has supporting information at journals.iucr.org/s

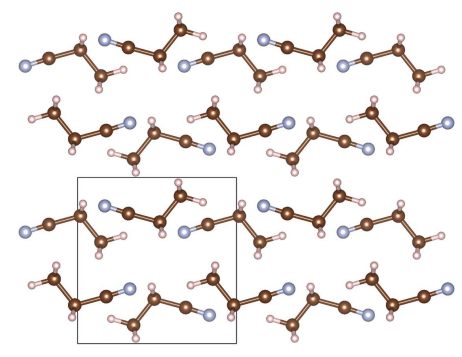

C 2020 International Union of Crystallography

\section{Crystal structure of propionitrile $\left(\mathrm{CH}_{3} \mathrm{CH}_{2} \mathrm{CN}\right)$ determined using synchrotron powder $\mathrm{X}$-ray diffraction}

\author{
Helen E. A. Brand, ${ }^{\mathrm{a} *}$ Qinfen Gu, ${ }^{\mathrm{a}}$ Justin A. Kimpton, ${ }^{\mathrm{a}}$ Rebecca Auchettl ${ }^{\mathrm{a}}$ and \\ Courtney Ennis ${ }^{b, c}$
}

aAustralian Synchrotron, ANSTO, 800 Blackburn Road, Clayton, Victoria 3168, Australia, ${ }^{\mathbf{b}}$ University of Otago,
PO Box 56, Dunedin 9054, New Zealand, and ${ }^{\mathbf{D}}$ Department of Chemistry and Physics, La Trobe Institute for
Molecular Sciences, La Trobe University, Victoria 3086, Australia. *Correspondence e-mail: helenb@ansto.gov.au

The structure and thermal expansion of the astronomical molecule propionitrile have been determined from 100 to $150 \mathrm{~K}$ using synchrotron powder X-ray diffraction. This temperature range correlates with the conditions of Titan's lower stratosphere, and near surface, where propionitrile is thought to accumulate and condense into pure and mixed-nitrile phases. Propionitrile was determined to crystallize in space group, Pnma (No. 62), with unit cell $a=$ 7.56183 (16) $\AA, b=6.59134$ (14) $\AA, c=7.23629$ (14), volume = 360.675 (13) $\AA^{3}$ at $100 \mathrm{~K}$. The thermal expansion was found to be highly anisotropic with an eightfold increase in expansion between the $c$ and $b$ axes. These data will prove crucial in the computational modelling of propionitrile-ice systems in outer Solar System environments, allowing us to simulate and assign vibrational peaks in the infrared spectra for future use in planetary astronomy.

\section{Introduction}

Propionitrile (ethyl cyanide; $\mathrm{CH}_{3} \mathrm{CH}_{2} \mathrm{CN}$ ) is an aliphatic nitrile commonly used as a solvent in chemical synthesis. Beyond Earth, gas-phase $\mathrm{CH}_{3} \mathrm{CH}_{2} \mathrm{CN}$ has been identified in a number of astrophysical environments. The strong dipole moment associated with the cyanide group $(\mu=4.011 \mathrm{D}$ : Kraśnicki \& Kisiel, 2011) has led to the millimetre-wave detection of $\mathrm{CH}_{3} \mathrm{CH}_{2} \mathrm{CN}$ in the Orion nebula and molecular cloud Sagittarius B2 (Johnson et al., 1977), as well as within the atmosphere of Saturn's moon Titan (Cordiner et al., 2015). On Titan, $\mathrm{CH}_{3} \mathrm{CH}_{2} \mathrm{CN}$ is formed by neutral and ion chemistry between the photolytic products of molecular nitrogen and methane gas (Krasnopolsky, 2009; Dobrijevic et al., 2016). Due to its low reactivity, $\mathrm{CH}_{3} \mathrm{CH}_{2} \mathrm{CN}$ is then thought to accumulate in the lower stratosphere before nucleation and growth of ices and aerosols (Coustenis et al., 1999). However, the presence of pure $\mathrm{CH}_{3} \mathrm{CH}_{2} \mathrm{CN}$ ice has yet to be conclusively identified at these altitudes (Samuelson et al., 2007) as opposed to other small nitriles that have been confirmed using infrared spectroscopy (Khanna, 2005). This leaves the required atmospheric sink for $\mathrm{CH}_{3} \mathrm{CH}_{2} \mathrm{CN}$ as an open question. It follows that mixed-phase cyanide ices incorporating $\mathrm{CH}_{3} \mathrm{CH}_{2} \mathrm{CN}$ have been proposed as the origin of Titan's mysterious $220 \mathrm{~cm}^{-1}$ feature (de Kok et al., 2007; Jennings et al., 2012). Concerning laboratory work on the condensed phase of $\mathrm{CH}_{3} \mathrm{CH}_{2} \mathrm{CN}$, infrared studies have been performed in cryogenic matrices (Toumi et al., 2015) and thin films (DelloRusso \& Khanna, 1996; Moore et al., 2010), as well as in the pure aerosol form 
(Ennis et al., 2017a). The latter investigation infers that a transition between two crystal phases may exist in the narrow temperature region between its $\sim 170 \mathrm{~K}$ melting point and $150 \mathrm{~K}$. This mirrors the phase dependence of related acetonitrile $\left(\mathrm{CH}_{3} \mathrm{CN}\right)$, which displays both low-temperature $(\alpha$ phase: $<160 \mathrm{~K})$ and high-temperature ( $\beta$-phase: $160-170 \mathrm{~K})$ crystal structures (Antson et al., 1987; Torrie \& Powell, 1992; Enjalbert \& Galy, 2002). Interestingly, it is often a metastable $\beta$-phase observed for low-temperature experiments involving the rapid condensation of $\mathrm{CH}_{3} \mathrm{CN}$ ice (thin film and aerosol studies) due to the re-ordering of established dipole-dipole interactions being kinetically hindered (Tizek et al., 2004).

Surprisingly for a common laboratory solvent, crystalline propionitrile has not yet been investigated by diffraction techniques. To bridge this gap in the fundamental solid-state structure of $\mathrm{CH}_{3} \mathrm{CH}_{2} \mathrm{CN}$, this article reports on the results of a synchrotron powder X-ray diffraction study to (i) solve its low-temperature crystal structures and (ii) observe the thermal expansion behaviour of $\mathrm{CH}_{3} \mathrm{CH}_{2} \mathrm{CN}$ ice between 100 and $150 \mathrm{~K}$. The determination of space group, lattice parameters and atomic coordinates has allowed our workgroup to undertake periodic density functional theory vibrational analysis (Civalleri et al., 2007; Ennis et al., 2017b) to assign and publish far-infrared spectra of $\mathrm{CH}_{3} \mathrm{CH}_{2} \mathrm{CN}$ ice obtained using a synchrotron source at temperatures consistent with Titan's atmosphere (Ennis et al., 2018).

\section{Sample preparation and data collection}

The solvent sample (Sigma Aldrich, $\geq 99$ GC Grade) was loaded into a $0.7 \mathrm{~mm}$-diameter quartz glass capillary and mounted onto the powder diffraction beamline at the Australian Synchrotron (AS) (Wallwork et al., 2007). The beamline was set up with a nominal wavelength of $1.0 \AA$; the wavelength was determined accurately using NIST SRM LaB 6 $660 \mathrm{~b}$ to be 0.99998 (1) $\AA$. The sample was initially cooled to $100 \mathrm{~K}$ at $6 \mathrm{~K} \mathrm{~min}^{-1}$ using an Oxford Cryosystems Cryostream 700 and allowed to equilibrate for $10 \mathrm{~min}$ before the temperature was increased to $150 \mathrm{~K}$ where it was again allowed to equilibrate before a second cool to $100 \mathrm{~K}$. Data were then collected upon warming in steps of $10 \mathrm{~K}$ from 100 to $150 \mathrm{~K}$. Data were collected using the Mythen II microstrip detector (Schmitt et al., 2003) from 3 to $83^{\circ}$ in $2 \theta$. To cover the gaps between detector modules, two data sets, each of $5 \mathrm{~min}$ in duration, were collected with the detector set $5^{\circ}$ apart and these were then merged to give a single data set. Merging was performed using the in-house software PDViPER. A slit size of $2 \mathrm{~mm}$ was used, to ensure that the fraction of the capillary illuminated by the $\mathrm{X}$-ray beam was the same as the isothermal zone on the cryostream. The capillary was rotated at $\sim 1 \mathrm{~Hz}$ during data collection to aid powder averaging. The cryostream equipment was calibrated at the beamline using a range of melting-point and phase-transition standards. Once these calibrations are applied, at the ramp rate used in this experiment, temperatures are accurate to within $1 \mathrm{~K}$ of the reported value.

\section{Structure determination}

The first $40^{\circ}$ in $2 \theta$ of the $100 \mathrm{~K}$ dataset was indexed using TOPAS 5 software (Bruker AXS), to an orthorhombic unit cell. There is a broad impurity peak around $15.68^{\circ}$. The space group Pna2 ${ }_{1}$ (No. 33) was first assigned from analysis of the systematic absences. The reflection intensities were extracted using a Pawley fit with $R_{\mathrm{wp}}=4.163 \%$. The first attempt at structure solution, using the powder charge-flipping (CF) algorithm implemented in Superflip (Palatinus \& Chapuis, 2007), was unsuccessful due to the high degree of preferred orientation (PO) of the sample. The crystal structure was then solved using a combination of the $\mathrm{CF}$ algorithm and the direct space method (with simulated annealing). After several trials with different preferred orientation settings, sixth-order spherical harmonic functions gave the best result. The $\mathrm{CH}_{3} \mathrm{CH}_{2} \mathrm{CN}$ molecule was defined as a rigid body unit in the simulated annealing procedure with idealized bond lengths $(\mathrm{C}-\mathrm{H}=1.0 \AA, \mathrm{C}-\mathrm{N}=1.16 \AA, \mathrm{C}-\mathrm{C}=1.53 \AA)$ and bond angles from the ICDD organic database. Further symmetry analysis showed a higher possible symmetry in a nonisomorphic supergroup with the space group Pnma (No. 62). A subsequent Pawley fitting in Pnma gave $R_{\mathrm{wp}}=4.197 \%$, which is very similar to the fit given in the lower-symmetry space group Pna2 ${ }_{1}$.

Rietveld structural refinement was then conducted for this compound using this structural model in Pnma as shown in Fig. 1. All atomic bond lengths were set with restraints (less than $15 \%$ of the idealized bond values), while all bond angles were free to refine. The atomic displacement parameters of all atoms were constrained to be the same value. The Rietveld fit to the experimental powder $\mathrm{X}$-ray diffraction data is excellent, yielding the agreement factors $R_{\mathrm{wp}}=4.91 \%, R_{\mathrm{B}}=1.51 \%$, goodness of fit $(\mathrm{GoF})=2.658$. No additional atoms could be located by using difference Fourier maps. Table 1 provides details of the experimental setup and crystallographic results

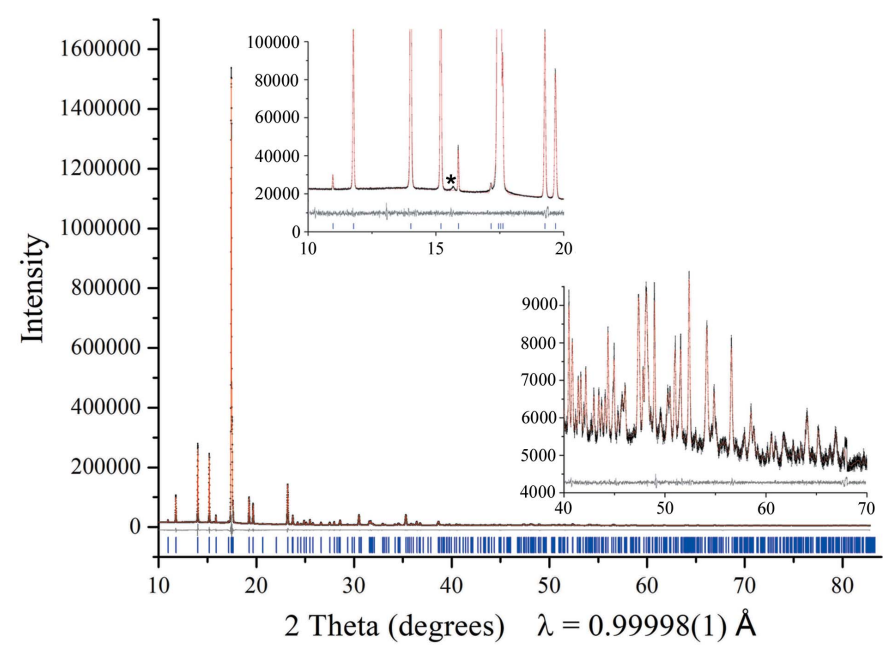

Figure 1

Rietveld fit of the proposed structural model (red) to observed diffraction data (black) at $100 \mathrm{~K}$. The grey difference plot is shown below the data. Bragg peak positions are shown as blue bars. Note that there is a broad impurity peak around $15.68^{\circ}$ marked by the asterisk $(*)$. 
Table 1

Experimental details.

\begin{tabular}{ll}
\hline Chemical formula & $\mathrm{C}_{3} \mathrm{H}_{5} \mathrm{~N}$ \\
Formula weight & $55.08 \mathrm{~g} \mathrm{~mol}^{-1}$ \\
Crystal system & Orthorhombic \\
Space group & Pnma $($ No. 62) \\
Cell parameters & $a=7.56183(16) \AA$ \\
& $b=6.59134(14) \AA$ \\
& $c=7.23629(14) \AA$ \\
Cell volume & $360.675(13) \AA^{3}$ \\
$Z$ & 4 \\
Calculated density & $1.01427 \mathrm{~g} \mathrm{~cm}^{-3}$ \\
$R_{\mathrm{B}}$ & $1.51 \%$ \\
$R_{\mathrm{wp}}$ & $4.91 \%$ \\
GoF & 2.658 \\
$2 \theta$ & $2 \theta_{\min }=3^{\circ} ; 2 \theta_{\text {max }}=83^{\circ}$ \\
Measured temperature & $100 \mathrm{~K}$ \\
Diffractometer & Mythen-II, PD beamline \\
Radiation type & Synchrotron, AS \\
Wavelength & $0.99998(1) \AA$ \\
\hline
\end{tabular}

Table 2

Fractional atomic coordinates for propionitrile at $100 \mathrm{~K}$.

Wyck $=$ Wyckoff position. SOF $=$ standard occupancy factor.

\begin{tabular}{lllllll}
\hline Atom & Wyck & SOF & $x / a$ & $y / b$ & $z / c$ & $B$ \\
\hline $\mathrm{N} 1$ & $4 \mathrm{c}$ & 1 & $0.1711(2)$ & $1 / 4$ & $0.8291(2)$ & $2.02(4)$ \\
$\mathrm{C} 1$ & $4 \mathrm{c}$ & 1 & $0.1110(3)$ & $1 / 4$ & $0.3522(3)$ & $2.02(4)$ \\
$\mathrm{C} 2$ & $4 \mathrm{c}$ & 1 & $0.2684(3)$ & $1 / 4$ & $0.4826(3)$ & $2.02(4)$ \\
$\mathrm{C} 3$ & $4 \mathrm{c}$ & 1 & $0.2172(2)$ & $1 / 4$ & $0.6802(3)$ & $2.02(4)$ \\
$\mathrm{H} 1$ & $8 \mathrm{~d}$ & 1 & $0.0305(12)$ & $0.3779(15)$ & $0.3661(15)$ & $2.02(4)$ \\
$\mathrm{H} 2$ & $8 \mathrm{~d}$ & 1 & $0.3419(13)$ & $0.1230(11)$ & $0.4658(14)$ & $2.02(4)$ \\
$\mathrm{H} 3$ & $4 \mathrm{c}$ & 1 & $0.149(2)$ & $1 / 4$ & $0.212(2)$ & $2.02(4)$ \\
\hline
\end{tabular}

obtained. Due to the weak scattering of $\mathrm{H}$ atoms from X-rays, we next conducted first-principles calculations to determine the optimized crystal structure. Density functional theory (DFT) calculations were conducted with the VASP 5.4.4 code (Kresse \& Hafner, 1993) on Australian Synchrotron Computer Infrastructure (ACSI). The generalized gradient approximation (Kresse \& Hafner, 1993) with a Perdew-BurkeErnzerhof (Perdew et al., 1996) exchange correlation function was used. The atomic potentials of $\mathrm{C} 2 s^{2} 2 p^{2}, \mathrm{~N} 2 s^{2} 2 p^{3}$ and $\mathrm{H} 1 s^{1}$ were treated by ultra-soft pseudo potentials (Kresse \& Joubert, 1999). The zero damping DFT-D3 dispersion correction method of Grimme was used to account for the significance of van der Waals interactions in the system (Larijani et al., 2017). The cut-off energy of $800 \mathrm{eV}$ and Monkhorst Pack $k$-point of $5 \times 5 \times 5$ were used to converge the total energy of the system within $1 \mathrm{meV}$ atom $^{-1}$. In the structural relaxation calculation, all atoms were allowed to relax within a fixed unit cell.

\section{Crystal structure description}

Fig. 2 shows the structure of $\mathrm{CH}_{3} \mathrm{CH}_{2} \mathrm{CN}$ viewed along each crystallographic axis in $2 \times 2 \times 2$ unit cells. Propionitrile was determined to crystallize in space group Pnma (No. 62), with unit cell $a=7.56183$ (16) $\AA, b=6.59134$ (14) $\AA, c=$ 7.23629 (14), volume $=360.675(13) \AA^{3}$ at $100 \mathrm{~K}$. Fractional atomic coordinates can be found in Table 2. Crystallographic density is calculated to be $1.01427 \mathrm{~g} \mathrm{~cm}^{-3}$. The $\mathrm{CH}_{3} \mathrm{CH}_{2} \mathrm{CN}$ molecules are arranged in chains along the $c$-axis which form layers in the ac plane. The $\mathrm{CH}_{3} \mathrm{CH}_{2} \mathrm{CN}$ molecules are reversed in their orientation in neighbouring chains along the $a$-axis. The planes are stacked along the $b$-axis with an interplane distance of 3.295 (1) $\AA$.

The arrangement of $\mathrm{CH}_{3} \mathrm{CH}_{2} \mathrm{CN}$ molecules within the crystalline structure is almost identical to the gas-phase monomer $r_{\mathrm{s}}$-structure (Table 3), as determined by analysis of the microwave spectra recorded from selected $\mathrm{CH}_{3} \mathrm{CH}_{2} \mathrm{CN}$ isotopologues (Heise et al., 1974). In the latter $r_{\mathrm{s}}$-structure, the molecule deviates slightly from $C_{\mathrm{s}}$ symmetry, with disparate bond-lengths for the internal $\mathrm{CH}_{3}$ group resulting in a rotated minimum and the $\mathrm{CCN}$ angle measured less than the expected
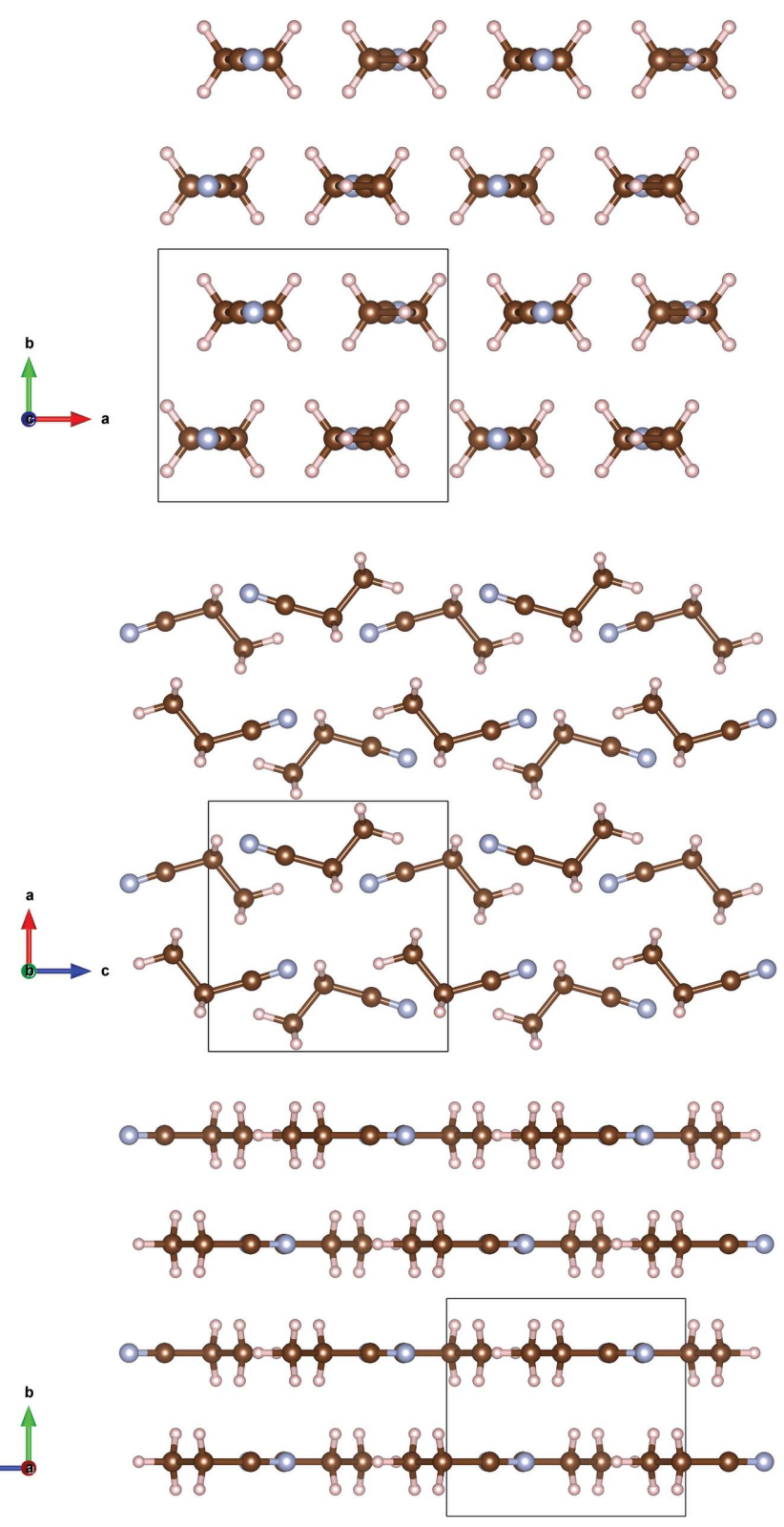

Figure 2

Packing of $\mathrm{CH}_{3} \mathrm{CH}_{2} \mathrm{CN}$ presented in $2 \times 2 \times 2$ unit-cells. Nitrogen is blue, carbon brown and hydrogen pink. 
Table 3

Structural parameters of $\mathrm{CH}_{3} \mathrm{CH}_{2} \mathrm{CN}$ at $100 \mathrm{~K}$ compared with experimental gas-phase values.

\begin{tabular}{|c|c|c|c|c|c|c|c|c|}
\hline \multicolumn{4}{|c|}{ Bond lengths } & \multicolumn{5}{|c|}{ Bond angles } \\
\hline Atom 1 & Atom 2 & $\begin{array}{l}\text { Bond } \\
\text { length }(\AA)\end{array}$ & $\begin{array}{l}\text { Gas-phase } \\
\text { molecule } \dagger\end{array}$ & Atom 1 & $\begin{array}{l}\text { Central } \\
\text { atom }\end{array}$ & Atom 3 & Angle $\left(^{\circ}\right)$ & $\begin{array}{l}\text { Gas-phase } \\
\text { molecule } \dagger\end{array}$ \\
\hline N1 & $\mathrm{C} 3$ & $1.1325(3)$ & $1.159(1)$ & N1 & $\mathrm{C} 3$ & $\mathrm{C} 2$ & $177.2(2)$ & 178.73 \\
\hline $\mathrm{C} 1$ & $\mathrm{C} 2$ & $1.5189(3)$ & $1.537(1)$ & $\mathrm{C} 3$ & $\mathrm{C} 2$ & $\mathrm{C} 1$ & $113.3(2)$ & 111.98 \\
\hline \multirow[t]{2}{*}{$\mathrm{C} 2$} & $\mathrm{C} 3$ & $1.481(3)$ & $1.459(1)$ & & & & & \\
\hline & & & & $\mathrm{C} 3$ & $\mathrm{C} 2$ & $\mathrm{H} 2$ & $105.0(6)$ & 108.13 \\
\hline \multirow[t]{2}{*}{$\mathrm{C} 2$} & $\mathrm{H} 2$ & $1.01(8)$ & $1.094(1)$ & $\mathrm{C} 1$ & $\mathrm{C} 2$ & $\mathrm{H} 2$ & $110.8(5)$ & 110.62 \\
\hline & & & & $\mathrm{C} 2$ & $\mathrm{C} 1$ & $\mathrm{H} 1$ & $113.4(5)$ & 111.08 \\
\hline $\mathrm{C} 1$ & H1 & $1.045(9)$ & $1.079(18)$ & $\mathrm{C} 2$ & $\mathrm{C} 1$ & $\mathrm{H} 3$ & $112.6(8)$ & 110.47 \\
\hline \multirow[t]{2}{*}{$\mathrm{C} 1$} & $\mathrm{H} 3$ & $1.05(1)$ & $1.091(1)$ & & & & & \\
\hline & & & & \multicolumn{3}{|c|}{ Dihedral angle $(\mathrm{H} 3 \mathrm{C} 1-\mathrm{C} 2 \mathrm{H} 2)$} & $62.243(9)$ & 59.31 \\
\hline
\end{tabular}

$\dagger$ Heise, Lutz \& Dreizler (1974), $r_{\mathrm{s}}$-structure.

Table 4

Thermal expansion parameters of solid $\mathrm{CH}_{3} \mathrm{CH}_{2} \mathrm{CN}$.

\begin{tabular}{llll}
\hline & $a$-axis & $b$-axis & $c$-axis \\
\hline$a\left(\mathrm{~K}^{-2}\right)$ & - & $6.598 \times 10^{-6}$ & $8.308 \times 10^{-7}$ \\
$b\left(\mathrm{~K}^{-1}\right)$ & $1.094 \times 10^{-3}$ & $1.260 \times 10^{-4}$ & $1.148 \times 10^{-4}$ \\
$L_{0}(\AA)$ & 7.453 & 6.514 & 7.217 \\
$R^{2}(\%)$ & 99.98 & 99.94 & 99.86 \\
\hline
\end{tabular}

$180^{\circ}$. The two internal $\mathrm{C}-\mathrm{C}$ bond lengths suggest a degree of double-bond character over the aliphatic backbone of the molecule (Lerner \& Dailey, 1957). This is mirrored in the molecular structure upon crystallization with relatively minor deviation from the gas-phase structure. The maximum deviation is $4 \%$ reduction in the $\mathrm{C}-\mathrm{H}$ bond lengths on the methyl group. This is unsuprising as X-ray measurements are least sensitive to hydrogen positions.

All bond angles are observed to be similarly identical from crystalline to gas-phase, particularly those associated with the $\mathrm{C}-\mathrm{H}$ aliphatic hydrogens where deviation is of the order of $2-3^{\circ}$ while the aliphatic carbon backbone only displays a slight opening of less than $2^{\circ}$. The dihedral angle as measured from the carbon backbone is $62.2(9)^{\circ}$, again only a $3^{\circ}$ deviation.

Between the molecules within the structure, the $\mathrm{H} 2$ hydrogen of the $\mathrm{CH}_{3}$ moiety is coordinated toward the lone electron pair of the nitrile $\mathrm{N} 1$ atom associated with the neighbouring molecule at an interatomic distance of 2.65 (8) $\AA$. There appears to be no close packing of neighbouring nitrile groups indicating that dipole-dipole interactions are secondary to interactions between intermolecular $\mathrm{C}-\mathrm{H}$ and nitrile moieties.

\section{Thermal expansion of propionitrile}

The volume thermal expansion of $\mathrm{CH}_{3} \mathrm{CH}_{2} \mathrm{CN}$ between 100 and $150 \mathrm{~K}$ can be described simply using a polynomial of the form: $V=a T^{2}+b T+V_{0}$, where $a=4.237$ (1) $\times 10^{-4}, b=$ $6.051(1) \times 10^{-2}$ and $V_{0}=350.53(1)$, with an agreement of $R^{2}=99.95 \%$. The lack of data points means that it is not reasonable to further manipulate the data to, for example, extract the expansivity tensor. Fig. 3 shows the volume expansion of the unit cell. The unit-cell axes have also been fitted with polynomials, the $a$ - and $c$-axes with a second-order polynomial and the $b$-axis with a linear fit. These coefficients are shown in Table 4.

Fig. 4 shows the relative axial expansivities of the unit-cell axes. The $b$-axis has the highest expansivity: at $150 \mathrm{~K}$ it is double that of the $a$-axis and eight times the $c$-axis. This is not unexpected as monomers are held together by hydrogen bonding only parallel to the $b$-axis - see Fig. 2 .

In order to easily compare the expansivity of $\mathrm{CH}_{3} \mathrm{CH}_{2} \mathrm{CN}$ with ice, the polynomial fit to the data has been differentiated and used in equation (1),

$$
a_{v}=\frac{1}{V_{0}}\left(\frac{\partial V}{\partial T}\right) .
$$

Fig. 5 shows the experimental expansivity determined here for $\mathrm{CH}_{3} \mathrm{CH}_{2} \mathrm{CN}$ compared with that of ice $1_{\mathrm{h}}$ over the same temperature range. The expansivity of $\mathrm{CH}_{3} \mathrm{CH}_{2} \mathrm{CN}$ is similar to ice $1_{\mathrm{h}}$ in magnitude and linearity, which follows from the

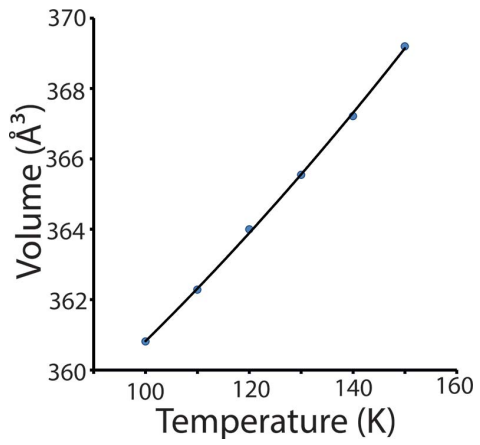

Figure 3

Thermal expansion of unit-cell volume for solid $\mathrm{CH}_{3} \mathrm{CH}_{2} \mathrm{CN}$ between 100 and $150 \mathrm{~K}$. Errors are approximately the same size as the data points.

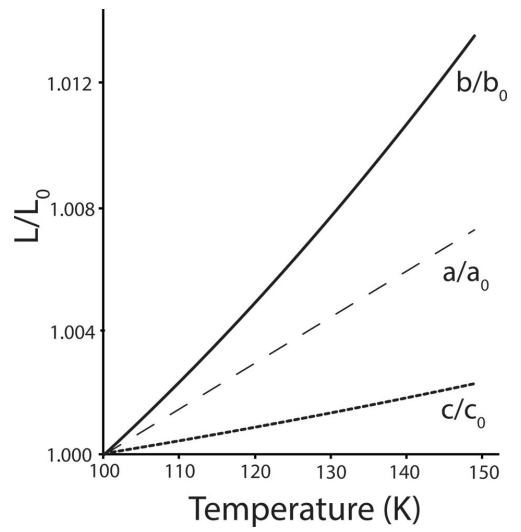

Figure 4

Relative expansivities of the unit-cell axes between 100 and $150 \mathrm{~K}$. The $a$-axis is represented by a dotted line, the $b$-axis by a dashed line and the $c$-axis by a full line. The ' 0 ' subscript denotes that the expansions are relative to the lowest temperature value. 


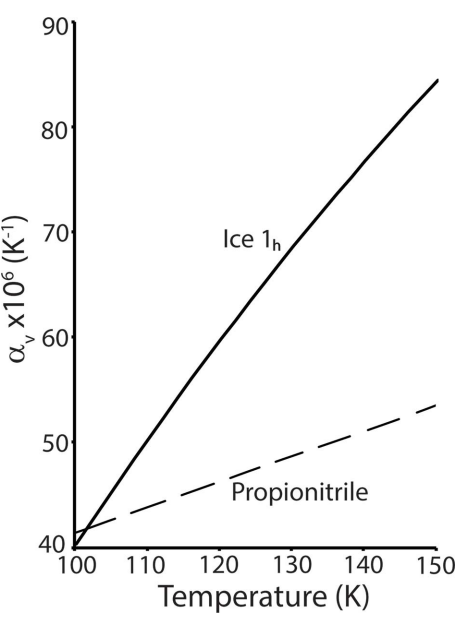

Figure 5

Relative volume expansivity of propionitrile compared with ice $1_{\mathrm{h}}$ after Röttger et al. (1994).

simplicity and few data points of the form of the volume expansion data for $\mathrm{CH}_{3} \mathrm{CH}_{2} \mathrm{CN}$.

\section{Summary and future directions}

Synchrotron X-ray powder diffraction has been used to determine the crystal structure and thermal expansion of $\mathrm{CH}_{3} \mathrm{CH}_{2} \mathrm{CN}$ from 100 to $150 \mathrm{~K}$ under ambient pressure conditions. The $\mathrm{CH}_{3} \mathrm{CH}_{2} \mathrm{CN}$ molecules are arranged in chains along the $c$-axis.

The volume thermal expansion is positive and similar in magnitude to that of ice $1_{\mathrm{h}}$ under the same conditions. However, the expansivity of ice $1_{\mathrm{h}}$ increases at a higher rate than that of $\mathrm{CH}_{3} \mathrm{CH}_{2} \mathrm{CN}$ suggesting the two may have complex interactions in environments where they are found together. The expansivity of $\mathrm{CH}_{3} \mathrm{CH}_{2} \mathrm{CN}$ is more in line with that of materials such as highly hydrated sulfates found in the Jovian system.

The small variation between the gas-phase molecular structure and that observed here is likely a result of a differing measurement temperature: $200 \mathrm{~K}$ in the literature and $100 \mathrm{~K}$ here. The changes in specific bond lengths and angles may give a hint to the important structural constructs which control the thermal expansion.

However, they are merely hints and further X-ray powder diffraction measurements are warranted, perhaps combined with neutron diffraction measurements, over a more granular temperature range to obtain details of the behaviour of the hydrogen-bonding network and elastic strain tensor. This and a full investigation of the phase relations of the $\mathrm{CH}_{3} \mathrm{CH}_{2} \mathrm{CN}-$ $\mathrm{H}_{2} \mathrm{O}$ system will be crucial if we are to understand the behaviour of $\mathrm{CH}_{3} \mathrm{CH}_{2} \mathrm{CN}$ over the range of temperatures found from the surface of Titan through the atmosphere to the Orion nebula.

\section{Funding information}

This work was carried out on the powder diffraction beamline at the Australian synchrotron; supported by Australian Research Council via the Discover Early Career Research
Award (DE150100301). RA was supported by an Australian Government Research Training Program (RTP) Scholarship. RA also thanks the Australian Institute of Nuclear Science and Engineering (AINSE) for their financial support under the AINSE Postgraduate Research Award (PGRA) scheme to enable this work

\section{References}

Antson, O. K., Tilli, K. J. \& Andersen, N. H. (1987). Acta Cryst. B43, 296-301.

Civalleri, B., Doll, K. \& Zicovich-Wilson, C. M. (2007). J. Phys. Chem. $B, 111,26-33$.

Cordiner, M. A., Palmer, M. Y., Nixon, C. A., Irwin, P. G. J., Teanby, N. A., Charnley, S. B., Mumma, M. J., Kisiel, Z., Serigano, J., Kuan, Y. J., Chuang, Y. L. \& Wang, K. S. (2015). Astrophys. J. 800, L14.

Coustenis, A., Schmitt, B., Khanna, R. K. \& Trotta, F. (1999). Planet. Space Sci. 47, 1305-1329.

de Kok, R., Irwin, P. G. J., Teanby, N. A., Nixon, C. A., Jennings, D. E., Fletcher, L., Howett, C., Calcutt, S. B., Bowles, N. E., Flasar, F. M. \& Taylor, F. W. (2007). Icarus, 191, 223-235.

Dobrijevic, M., Loison, J. C., Hickson, K. M. \& Gronoff, G. (2016). Icarus, 268, 313-339.

Enjalbert, R. \& Galy, J. (2002). Acta Cryst. B58, 1005-1010.

Ennis, C., Auchettl, R., Appadoo, D. R. T. \& Robertson, E. G. (2017b). Mon. Not. R. Astron. Soc. 471, 4265-4274.

Ennis, C., Auchettl, R., Appadoo, D. R. T. \& Robertson, E. G. (2018). Phys. Chem. Chem. Phys. 20, 23593-23605.

Ennis, C., Auchettl, R., Ruzi, M. \& Robertson, E. G. (2017a). Phys. Chem. Chem. Phys. 19, 2915-2925.

Heise, H. M., Lutz, H. \& Dreizler, H. (1974). Z. Naturforsch. A, 29, 1345.

Jennings, D. E., Anderson, C. M., Samuelson, R. E., Flasar, F. M., Nixon, C. A., Kunde, V. G., Achterberg, R. K., Cottini, V., de Kok, R., Coustenis, A., Vinatier, S. \& Calcutt, S. B. (2012). Astrophys. J. 754, L3.

Johnson, D. R., Lovas, F. J., Gottlieb, C. A., Gottlieb, E. W., Litvak, M. M., Thaddeus, P. \& Guelin, M. (1977). Astrophys. J. 218, 370376.

Khanna, R. K. (2005). Icarus, 178, 165-170.

Kraśnicki, A. \& Kisiel, Z. (2011). J. Mol. Spectrosc. 270, 83-87.

Krasnopolsky, V. A. (2009). Icarus, 201, 226-256.

Kresse, G. \& Hafner, J. (1993). Phys. Rev. B, 47, 558-561.

Kresse, G. \& Joubert, D. (1999). Phys. Rev. B, 59, 1758.

Larijani, H. T., Jahanshahi, M., Ganji, M. D. \& Kiani, M. H. (2017). Phys. Chem. Chem. Phys. 19, 1896-1908.

Lerner, R. G. \& Dailey, B. P. (1957). J. Chem. Phys. 26, 678-680.

Moore, M. H., Ferrante, R. F., James Moore, W. \& Hudson, R. (2010). Astrophys. J. Suppl. 191, 96-112.

Palatinus, L. \& Chapuis, G. (2007). J. Appl. Cryst. 40, 786-790.

Perdew, J. P., Burke, K. \& Ernzerhof, M. (1996). Phys. Rev. Lett. 77, 3865-3868.

Röttger, K., Endriss, A., Ihringer, J., Doyle, S. \& Kuhs, W. F. (1994). Acta Cryst. B50, 644-648.

Russo, N. D. \& Khanna, R. K. (1996). Icarus, 123, 366-395.

Samuelson, R. E., Smith, M. D., Achterberg, R. K. \& Pearl, J. C. (2007). Icarus, 189, 63-71.

Schmitt, B., Brönnimann, C., Eikenberry, E. F., Gozzo, F., Hörmann, C., Horisberger, R. \& Patterson, B. (2003). Nucl. Instrum. Methods Phys. Res. A, 501, 267-272.

Tizek, H., Grothe, H. \& Knözinger, E. (2004). Chem. Phys. Lett. 383, 129-133.

Torrie, B. H. \& Powell, B. M. (1992). Mol. Phys. 75, 613-622.

Toumi, A., Piétri, N. \& Couturier-Tamburelli, I. (2015). Phys. Chem. Chem. Phys. 17, 30352-30363.

Wallwork, K. S., Kennedy, B. J. \& Wang, D. (2007). AIP Conf. Proc. 879, 879-882. 